\title{
What factors accelerate aortic stiffening in hemodialysis patients? An observational study
}

\begin{abstract}
Tomoji Matsumae ${ }^{1}$, Kazuo Ueda ${ }^{1}$, Yasuhiro Abe ${ }^{2}$, Shinsuke Nishimura ${ }^{1}$, Genji Murakami ${ }^{1}$ and Takao Saito ${ }^{2}$
Increased aortic stiffness is an independent predictor of death from cardiovascular disease in patients with end-stage renal disease (ESRD). Various factors that contribute to carotid-femoral pulse wave velocity (cfPWV) as a surrogate of aortic stiffness have been identified, but determinants of long-term worsening of aortic stiffness remain to be elucidated. To clarify the factors that accelerate aortic stiffness in hemodialysis patients, 148 patients with ESRD on hemodialysis were evaluated. At baseline, cfPWV and ankle-brachial blood pressure index (ABPI) were measured and clinical status including biochemical parameters, with or without hepatitis $\mathrm{c}$ virus (HCV) infection, diabetes mellitus (DM), cardiovascular disease, cerebrovascular disease and peripheral arterial disease at baseline, were evaluated. The cfPWV was measured again after a 3-year follow up and the annual change in cfPWV was calculated. The cfPWV decreased in 54 patients, worsened slowly in 47 (annual change in cfPWV ranged from 0 to $0.33 \mathrm{~m} \mathrm{~s}^{-1}$ per year), and worsened rapidly in 47 patients (annual change in cfPWV was more than $0.33 \mathrm{~m} \mathrm{~s}^{-1}$ per year). The prevalences of DM, HCV infection and peripheral arterial disease were the highest in the rapid progression group. Univariate analysis showed that age, high-density lipoprotein cholesterol (HDL-C), low-density lipoprotein cholesterol (LDL-C), LDL-C/HDL-C ratio, HCV infection, ABPI and number of vasculopathies were significantly associated with annual change in cfPWV. Stepwise regression analysis identified ABPI, LDL-C/HDL-C ratio and HCV infection as independent determinants of worsening of cfPWV. Further studies are needed to investigate the mechanism of HCV-related enhancement of aortic stiffness in ESRD patients.
\end{abstract}

Hypertension Research (2010) 33, 243-249; doi:10.1038/hr.2009.219; published online 15 January 2010

Keywords: ankle-brachial blood pressure index; aortic pulse wave velocity; hemodialysis; hepatitis $\mathrm{C}$ virus

\section{INTRODUCTION}

Cardiovascular disease (CVD) accounts for more than $50 \%$ of deaths among patients with end-stage renal disease (ESRD). ${ }^{1,2}$ Large artery damage is prevalent in patients with ESRD and believed to contribute to increased cardiovascular disease mortality. Increased aortic stiffness, as assessed by pulse wave velocity (PWV), is an independent poor prognostic factor for cardiovascular disease and all-cause mortality in patients with ESRD. ${ }^{3,4}$ Several studies showed that age, vascular calcification, ${ }^{5,6}$ presence of diabetes mellitus ${ }^{6}$ and vertebral bone mineral density ${ }^{7}$ are determinants of aortic PWV in ESRD patients treated with hemodialysis (HD). Recently, we described that hemoglobin A1c was an independent contributor to aortic PWV not only in diabetic HD patients, but also in non-diabetic HD patients. ${ }^{8,9}$ However, there have been only a few studies that elucidated the factors that contribute to the rate of progression of arterial stiffening in ESRD patients treated with HD.

It is known that inflammation has a critical role in the pathogenesis of atherosclerosis, ${ }^{10,11}$ and that hepatitis $\mathrm{C}$ virus (HCV) infection is associated with increases in inflammatory makers. ${ }^{12,13}$ On the other hand, HCV infection is common in HD patients, ${ }^{14,15}$ and is associated with a higher all-cause and cardiovascular mortality, ${ }^{16,17}$ although it is not clear whether HCV infection per se reduces aortic compliance or not.

The aim of this observational study was to identify determinants of worsening of aortic stiffness during a 3-year follow-up period of ESRD patients treated with HD. Furthermore, the study focused on the effect of HCV on the development of aortic stiffening in ESRD patients.

\section{METHODS}

Study design and patients

In our previous cross-sectional study, ${ }^{9} 242$ patients who had been treated by regular HD for more than 6 months at Murakami Memorial Hospital, Japan, underwent measurements of carotid-femoral PWV (cfPWV) and ankle-brachial blood pressure index (ABPI). Of these, 148 patients who could be followed up after 3 years from baseline measurements were enrolled in this study. Patients in a critical state, for example, severe cerebrovascular disease, severe peripheral arterial disease with amputation of the lower extremity and/or active gangrene, severe joint deformity because of rheumatoid arthritis, uncontrolled malignancy, decompensated liver cirrhosis, aortic ste-

${ }^{1}$ Department of Internal Medicine, Kyorinkai Murakami Memorial Hospital, Nakatsu, Japan and ${ }^{2}$ Division of Nephrology and Rheumatology, Department of Internal Medicine, Fukuoka University School of Medicine, Fukuoka, Japan

Correspondence: Dr T Matsumae, Department of Internal Medicine, Kyorinkai Murakami Memorial Hospital, 1799, Muro-Machi, Nakatsu, Oita 871-0049, Japan.

E-mail: kyorin-m@arion.ocn.me.jp

Received 7 July 2009; revised 16 November 2009; accepted 27 November 2009; published online 15 January 2010 
nosis or regurgitation, were excluded from this study. The local ethics committee approved this study, and informed consent was obtained before the measurements.

\section{Data collection}

The clinical data were collected by chart review and interview. Data related to time on dialysis (months), smoking habits, macrovascular complications (for example, coronary artery disease (angina or previous myocardial infarction) and cerebrovascular disease (stroke or transient ischemic attack)) were checked in all patients. Patients with an ABPI of $<0.9$ or more than 1.4 were considered positive for peripheral vascular disease.

Blood chemistry was determined twice per month before HD session, and included measurement of calcium, phosphate and hematocrit. Serum albumin, high-sensitive C-reactive protein (hs-CRP) and $\beta$-2-microglobulin were measured once every month. Intact parathyroid hormone (i-PTH) was measured every 3 months. Hemoglobin Alc assay was performed monthly in diabetic patients and every 3 months in non-diabetic patients using latex immunoassay. We used the annual average values of the abovementioned blood biochemistry parameters of HD patients for analyses (if duration of HD was $<12$ months, we used the average values from the start of HD to examination).

Serological tests for anti-HCV antibodies using second-generation commercial enzyme immunoassays were performed semi-annually. Moreover, HCVRNA levels and genotype was determined for patients positive for anti-HCV antibodies. For RNA extraction, blood samples were collected before heparin administration. Patients positive for anti-HCV antibodies were considered free of HCV infection when HCV-RNA was not detected in the sample.

Blood samples for measurement of total cholesterol, triglyceride, highdensity lipoprotein cholesterol (HDL-C), low-density lipoprotein cholesterol (LDL-C) and fasting blood glucose were collected in the morning after an overnight fast of at least $12 \mathrm{~h}$. These measurements were performed within 4 weeks of measurements of cfPWV and ABPI at baseline.

\section{Measurements of aortic pulse wave velocity and ankle-brachial blood pressure index}

Aortic PWV was assessed by measuring cfPWV using a PWV meter (VaSera VS-1000, Fukuda Denshi, Tokyo, Japan) on the morning before a midweek HD session with the patient in a supine position after a 5-min bed rest. Pulse waves were recorded by using sensors placed on the skin at the right carotid and right femoral arteries. Heart sounds S1 and S2 were detected by a microphone placed on the right edge of the sternum at the level of the second intercostal space. The electrocardiogram was recorded with electrodes placed on both arms and the right leg. The PWV meter measures the time intervals between pulse waves at the carotid and femoral probes $(\mathrm{T})$, and between S2 and the notch of the carotid pulse wave (Tc). The cfPWV was calculated as follows:

$$
\operatorname{cfPWV}(\mathrm{m} / \mathrm{s})=1.3 \times L /(T+T c)
$$

where $L$ is the measured distance between the heart-sound microphone and the femoral probe. The actual distance between the aortic orifice and the femoral site is estimated to be $1.3 \times L .(T+T c)$ represents the time for the pulse wave to travel from the aortic orifice to the femoral artery. The PWV was measured for 10 consecutive pulses, and was the average used for analysis. The coefficient of variation of $\mathrm{PWV}$ was $<5 \%$.

ABPI was determined at the time of cfPWV measurement using the same device, which simultaneously measures the arm and ankle (brachial and posterior tibial) artery BP by oscillometry. ABPI represents the ratio of the lower value of the ankle systolic blood pressure (SBP) divided by the SBP of the arm without vascular access.

Follow-up measurements were performed 3 years from baseline measurement (average, 36.8 months, range, 36-39 months). The estimated annual change in cfPWV was calculated for each patient ((value at second examination - value at the first)/observation period (month) $\times 12 \mathrm{~m} \mathrm{~s}^{-1}$ per year).

\section{Statistical analysis}

Data are presented as mean \pm s.e.m. or actual numbers. The Mann-Whitney test was used to compare the clinical variables between patients with or without HCV infection. Analysis of variance followed by Tukey's test for pairwise comparisons was used to identify differences among three groups. Categorical variables were subjected to $\chi^{2}$-test as appropriate. Correlation analysis appropriate for normal (Pearson's correlation) and non-normal (Spearman's correlation) distribution was used to assess the associations of the estimated annual rate of increase in cfPWV with a number of other parameters. Correlations that were significant below the $10 \%$ level were entered into a stepwise regression model to determine the variables that independently influenced changes in cfPWV/year. Multiple logistic analysis was performed to determine the predictive factors for the fall in cfPWV during the follow-up period. A $P$-value $<0.05$ indicated statistical significance. All analyses were performed using a statistical software package (SPSS 11.0 for Windows, Chicago, IL, USA).

\section{RESULTS}

\section{Characteristics of study population}

Data of 148 patients (64 women) with a mean HD duration of 76.5 months were analyzed. All patients underwent hospital-based HD, with the majority on dialysis three times per week for $4 \mathrm{~h}$ each. The mean age was $62.4 \pm 1.0$ years (range, 23-82). The mean value of cfPWV at baseline was $9.57 \pm 0.17 \mathrm{~m} \mathrm{~s}^{-1}$, and increased significantly to $10.33 \pm 0.52 \mathrm{~m} \mathrm{~s}^{-1}$ at the end of the follow-up period $(P=0.002$ by paired $t$-test). Out of the 148 patients registered in this study, 48 were diabetics. HCV infection was diagnosed in 15 patients, but none of the 148 patients had HBV infection. All but one patient were infected with HCV before commencement of treatment with HD. One patient started HD in 1974, and therefore HCV infection could not be confirmed before or after HD introduction. Table 1 shows the profile of the patients at baseline with or without HCV infection. Serum albumin, total cholesterol and HDL-C were significantly lower in patients with HCV infection than in those without HCV infection. Table 2 lists the characteristics of the 15 patients with HCV infection as well as the values of the estimated annual change in cfPWV. The underlying pathology of renal failure in this group of patients was similar to that in patients without $\mathrm{HCV}$ infection. There was no relationship between the estimated annual change in cfPWV and serum alanine aminotransferase (ALT), serum aspartate aminotransferase (AST), platelets count, serum albumin or HCV-RNA genotype in 15 patients with HCV infection.

Patients were also divided into three groups according to the change in cfPWV during the study period. Fifty-four patients showed a decrease in the follow-up cfPWV and they were defined as the regression group. Out of the remaining 94 patients, 47 showed progression in the follow-up cfPWV of more than $0.33 \mathrm{~m} \mathrm{~s}^{-1}$ per year (rapid progression group). The other 47 patients showed a slower progression (range, $0-0.33 \mathrm{~m} \mathrm{~s}^{-1}$ per year) of cfPWV (slow progression group). Table 3 summarizes the baseline clinical characteristics of the three groups. The mean age of patients of the rapid progression group was significantly higher than those of the other two groups. SBP of the rapid progression group was significantly higher than that of the slow progression group. However, the male/female ratio, duration of $\mathrm{HD}$, body mass index (BMI) and diastolic blood pressure were similar among the three groups. The prevalences of diabetes and HCV infection were highest in the rapid progression group $(P=0.03$ for both prevalences, $\chi^{2}$-test). Serum albumin concentration of the slow progression group was higher than that of the other two groups. Both the total cholesterol and triglycerides were not significantly different among the three groups. HDL-C of the rapid progression group was lower than those of the other two groups and LDL-C of the rapid progression group was significantly higher than that of the regression group. Moreover, the LDL-C/HDL-C ratio of the rapid progression group was significantly higher than that of the regression group. Other blood tests were not different among the three groups. The prevalence of peripheral vascular disease, diagnosed by ABPI value $<0.9$ (none of 
Table 1 Baseline characteristics of the study cohort with or without HCV infection

\begin{tabular}{|c|c|c|c|}
\hline Parameters & $\begin{array}{l}\text { Patients } \\
\text { with HCV } \\
\text { infection }\end{array}$ & $\begin{array}{c}\text { Patients } \\
\text { without HCV } \\
\text { infection }\end{array}$ & P-value \\
\hline$n$ & 15 & 133 & \\
\hline Males & $11(73.3)$ & $73(54.9)$ & 0.27 \\
\hline Age (years) & $67.3 \pm 1.7$ & $61.8 \pm 1.1$ & 0.07 \\
\hline Duration of hemodialysis (months) & $58.8 \pm 22.9$ & $73.2 \pm 5.9$ & 0.21 \\
\hline Body mass index $\left(\mathrm{kg} \mathrm{m}^{-2}\right)$ & $21.7 \pm 0.9$ & $21.7 \pm 0.3$ & 0.73 \\
\hline Systolic blood pressure (mm Hg) & $166.7 \pm 9.2$ & $152.8 \pm 2.3$ & 0.12 \\
\hline Diastolic blood pressure (mm Hg) & $92.8 \pm 5.2$ & $90.4 \pm 1.2$ & 0.97 \\
\hline Diabetes mellitus & $7(46.7)$ & $41(30.8)$ & 0.25 \\
\hline Current smoking & $5(33.3)$ & $30(22.6)$ & 0.35 \\
\hline ACEI and/or ARB use & $7(46.7)$ & $55(41.4)$ & 0.78 \\
\hline Albumin $\left(\mathrm{g} \mathrm{dl}^{-1}\right)$ & $4.02 \pm 0.05$ & $4.14 \pm 0.03$ & 0.048 \\
\hline Adjusted calcium (mg per 100 ml) & $8.82 \pm 0.23$ & $9.20 \pm 0.07$ & 0.13 \\
\hline Phosphate (mg per $100 \mathrm{ml}$ ) & $5.30 \pm 0.29$ & $5.62 \pm 0.10$ & 0.38 \\
\hline Calcium-phosphate product & $46.3 \pm 3.0$ & $51.5 \pm 1.0$ & 0.12 \\
\hline Intact parathormone $\left(\mathrm{ng} \mathrm{ml}^{-1}\right)$ & $109 \pm 16$ & $124 \pm 11$ & 0.59 \\
\hline Total cholesterol (mg per 100 ml) & $147.4 \pm 8.6$ & $170.1 \pm 3.1$ & 0.02 \\
\hline Triglycerides (mg per $100 \mathrm{ml}$ ) & $108.1 \pm 12.2$ & $114.0 \pm 4.8$ & 0.85 \\
\hline HDL-C (mg per 100 ml) & $34.1 \pm 2.4$ & $42.3 \pm 1.1$ & 0.02 \\
\hline LDL-C (mg per 100 ml) & $91.1 \pm 6.4$ & $104.8 \pm 2.7$ & 0.10 \\
\hline LDL-C/HDL-C ratio & $2.89 \pm 0.32$ & $2.76 \pm 0.11$ & 0.61 \\
\hline Hemoglobin A1C (\%) & $5.45 \pm 0.15$ & $5.61 \pm 0.09$ & 0.70 \\
\hline $\begin{array}{l}\text { High-sensitive c-reactive } \\
\text { protein (mg per } 100 \mathrm{ml} \text { ) }\end{array}$ & $0.263 \pm 0.058$ & $0.341 \pm 0.032$ & 0.45 \\
\hline \multicolumn{4}{|l|}{ Macrovascular complications } \\
\hline Coronary artery disease & 0 & $18(13.5)$ & 0.22 \\
\hline Stroke & $2(13.3)$ & $12(9.0)$ & 0.94 \\
\hline Peripheral vascular disease & $3(20.0)$ & $37(27.8)$ & 0.76 \\
\hline \multicolumn{4}{|l|}{ Number of macrovascular complications } \\
\hline 0 & $11(73.3)$ & $88(66.2)$ & 0.87 \\
\hline 1 & $3(20.0)$ & $30(22.6)$ & \\
\hline 2 & $1(9.1)$ & $10(7.5)$ & \\
\hline 3 & 0 & $5(3.8)$ & \\
\hline $\begin{array}{l}\text { Onset of macrovascular complications } \\
\text { during follow-up period }\end{array}$ & $3(20.0)$ & $20(14.9)$ & 0.71 \\
\hline $\operatorname{cfPWV}\left(\mathrm{m} \mathrm{s}^{-1}\right)$ & $8.89 \pm 0.43$ & $8.97 \pm 0.16$ & 0.97 \\
\hline $\mathrm{ABPI}$ & $0.989 \pm 0.046$ & $0.994 \pm 0.016$ & 0.84 \\
\hline
\end{tabular}

Abbreviations: ABPI, ankle-brachial blood pressure index; ACEI, angiotensin-converting enzyme inhibitor; ARB, angiotensin receptor blocker; cfPWV, carotid-femoral pulse wave velocity;

HDL-C high-density lipo rotein tho

the patients had ABPI more than 1.4), showed some variability among the three groups $\left(P=0.001, \chi^{2}\right.$-test). Furthermore, the distribution of the number of complications was different among the three groups $\left(P=0.01, \chi^{2}\right.$-test $)$.

\section{Determinants of aortic stiffening}

Table 4 shows the results of univariate analyses of the relationships between the estimated annual change in $\operatorname{cfPWV}\left(\mathrm{m} \mathrm{s}^{-1}\right.$ per year) and various clinical variables measured at baseline. A weak correlation was found between age at baseline and changes in cfPWV $(r=0.173$; $r=0.04)$. HDL-C also correlated negatively with changes in cfPWV $(r=-0.206 ; P=0.002)$, whereas LDL-C $(r=0.216 ; P=0.01)$ and the
Table 2 Clinical profile and annual change in carotid-femoral pulse wave velocity in patients with HCV infection

\begin{tabular}{|c|c|c|c|}
\hline & & $\begin{array}{c}\text { Annual change in } \\
\text { aortic pulse wave velocity } \\
\text { ( } \mathrm{ms}^{-1} \text { per year) }\end{array}$ & \\
\hline Parameters & n (\%) & Mean \pm s.e.m. & P-value \\
\hline Underlying disease of ESRD & & & 0.34 \\
\hline Diabetic nephropathy & $6(40.0)$ & $0.45 \pm 0.13$ & \\
\hline Chronic glomerulonephritis & $6(40.0)$ & $0.45 \pm 0.26$ & \\
\hline Hypertensive nephrosclerosis & $2(13.3)$ & $0.40 \pm 0.07$ & \\
\hline Polycystic kidney disease & $1(6.7)$ & -0.47 & \\
\hline Genotype & & & 0.94 \\
\hline $1 b$ & $11(73.3)$ & $0.38 \pm 0.13$ & \\
\hline $2 a$ & $4(26.7)$ & $0.36 \pm 0.27$ & \\
\hline Alanine aminotransferase & & & 0.18 \\
\hline$\leqslant 10$ & $5(33.3)$ & $0.68 \pm 0.09$ & \\
\hline $11-15$ & $5(33.3)$ & $0.27 \pm 0.23$ & \\
\hline$\geqslant 16$ & $5(33.3)$ & $0.18 \pm 0.32$ & \\
\hline Aspartate aminotransferase & & & 0.15 \\
\hline$\leqslant 10$ & $5(33.3)$ & $0.73 \pm 0.20$ & \\
\hline $11-20$ & $5(33.3)$ & $0.36 \pm 0.23$ & \\
\hline$\geqslant 21$ & $5(33.3)$ & $0.18 \pm 0.17$ & \\
\hline Serum albumin (mg per $100 \mathrm{ml}$ ) & & & 0.69 \\
\hline$\leqslant 4.0$ & $5(33.3)$ & $0.27 \pm 0.18$ & \\
\hline $4.1-4.2$ & $5(33.3)$ & $0.55 \pm 0.23$ & \\
\hline$\geqslant 4.3$ & $5(33.3)$ & $0.34 \pm 0.26$ & \\
\hline Platelet count $\left(\times 10^{4} \mathrm{~mm}^{-3}\right)$ & & & 0.44 \\
\hline$\leqslant 12$ & $5(33.3)$ & $0.12 \pm 0.22$ & \\
\hline $13-17$ & $6(40.0)$ & $0.52 \pm 0.19$ & \\
\hline$\geqslant 18$ & $4(26.7)$ & $0.43 \pm 0.30$ & \\
\hline
\end{tabular}

LDL-C/HDL-C ratio $(r=0.256 ; P=0.002$; Figure 1a) correlated positively with changes in cfPWV. Moreover, HCV infection and the number of macrovascular complications correlated positively with changes in cfPWV $(r=0.173 ; P=0.04, r=0.224 ; P=0.008$, respectively). ABPI correlated inversely with changes in cfPWV $(r=-0.289$; $P<0.001$; Figure 1b).

Stepwise multiple regression analysis identified ABPI, LDL-C/HDL-C ratio and $\mathrm{HCV}$ infection as the best determinants of estimated annual change in cfPWV (Table 5). The model suggested that a decrease of 0.1 in ABPI would produce a rise in the estimated annual change in $\mathrm{cfPWV}$ of $0.072 \mathrm{~m} \mathrm{~s}^{-1}$ per year. Furthermore, a rise of 0.5 in the LDL-C/HDL-C ratio would result in a $0.04 \mathrm{~m} \mathrm{~s}^{-1}$ per year increase and $\mathrm{HCV}$ infection would result in a $0.32 \mathrm{~m} \mathrm{~s}^{-1}$ per year increase in the estimated annual rate of increase in cfPWV.

Lastly, to determine the predictors of the fall in cfPWV during the follow-up period, multiple logistic analysis was performed. We entered the following variables into the analysis: age, sex, BMI, serum albumin, hs-CRP, calcium, ionized phosphorus, i-PTH, hemoglobin A1c and LDL-C/HDL-C ratio, use of angiotensin-converting enzyme inhibitors and/or angiotensin receptor blockers, HCV infection, previous macrovascular complications and diabetes. The analysis identified female sex (odds ratio $=2.71,95 \% \mathrm{CI}, 1.1-6.7, P=0.02$ ) and LDL-C/HDL-C ratio 
Table 3 Baseline characteristics of patients of the regression group, slow regression group and rapid progression group

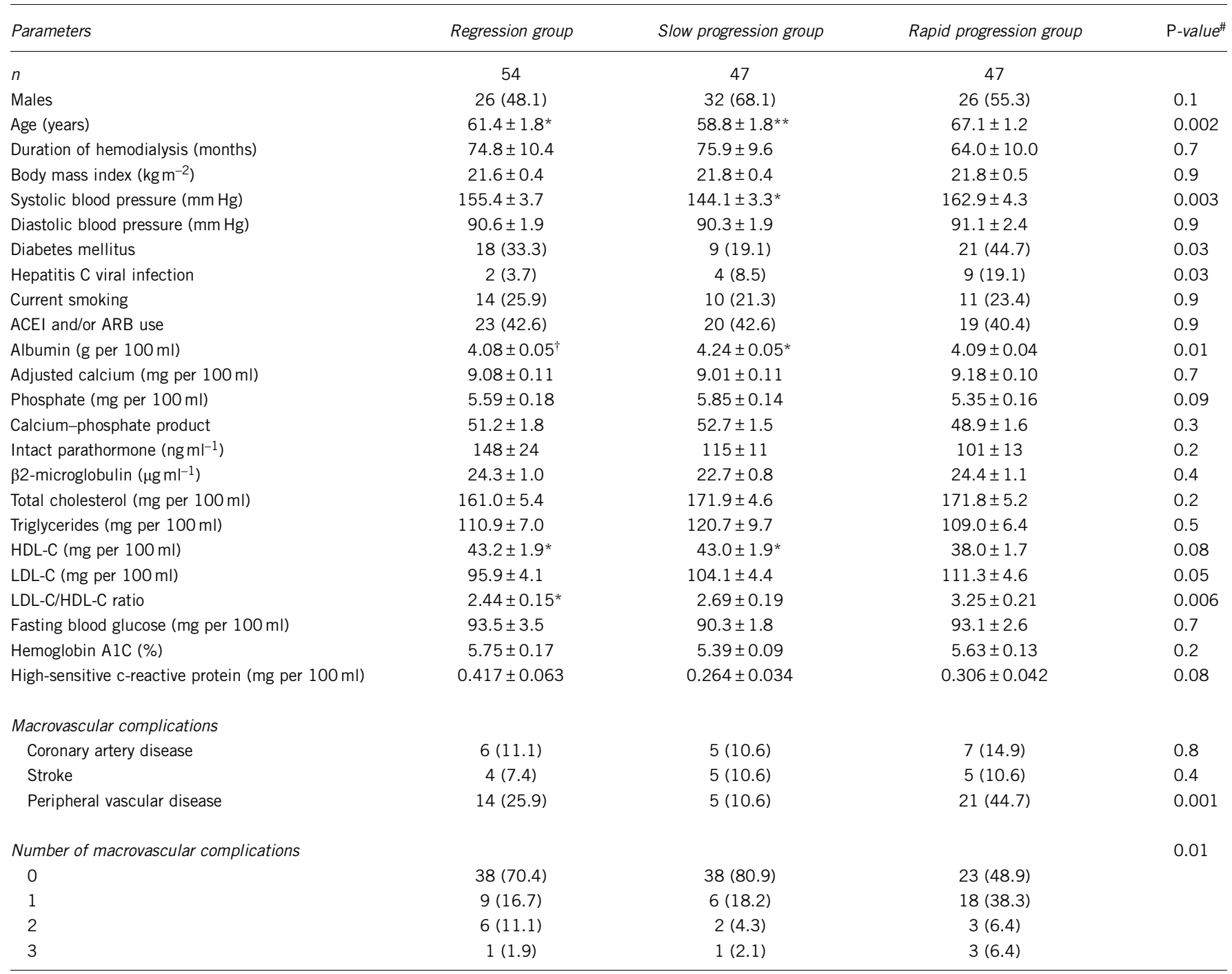

Abbreviations: ACEI, angiotensin-converting enzyme inhibitor; ARB, angiotensin receptor blocker; HDL-C, high-density lipoprotein cholesterol; LDL-C, low-density lipoprotein cholesterol. Data are mean \pm s.e.m. or number (percent).

\#Overall comparison among the three groups.

$* P<0.05$ vs. rapid progression group.

${ }^{* *} P<0.01$ vs. rapid progression group.

$P<0.05$ vs. slow progression group.

(odds ratio $=0.62,95 \% \mathrm{CI}, 0.41-0.93, P=0.02$ ) were significant predictors of the fall in cfPWV during the follow-up period.

\section{DISCUSSION}

Several studies have examined the determinants of aortic stiffness in ESRD patients, but there is limited information on determinants of progression of aortic stiffening in these patients. The result of this study showed that ABPI, LDL-C/HDL-C ratio at baseline and HCV infection independently determine and thus predict the increase in cfPWV in ESRD patients treated with HD. Previous studies suggested a link between infection with microorganisms such as Chlamydia pneumonia ${ }^{18}$ cytomegalovirus, ${ }^{19}$ Helicobacter pylor ${ }^{20}$ and herpes simplex virus, ${ }^{21}$ and increased the risk of cardiovascular diseases; however, the atherogenic effect of viral hepatitis remains controversial. A study of the northeast German population reported no correlation between various serological markers for $\mathrm{HBV}$ and $\mathrm{HCV}$ infection and the risk of atherosclerosis. ${ }^{22}$ In Japanese subjects, infection with HBV or HCV did not influence the severity of arteriosclerosis. ${ }^{23}$ Moreover, chronic HBV and HCV infections were not associated with the presence or severity of coronary artery disease. ${ }^{24}$ On the other hand, Ishizaka et al. ${ }^{25}$ reported that HCV seropositivity was independently associated with carotid arterial plaque and carotid intima-media thickening in 4784 individuals who underwent a general health screening test. With regard to ESRD patients, Oyake et al. ${ }^{26}$ indicated that HCV infection was associated with increased aortic stiffness and cardiovascular events in HD patients. Our results are in agreement with theirs, although differences in study design should be considered. The above associations between HCV infection and progression of atherosclerosis in the above studies ${ }^{25,26}$ are, however, studied in crosssectional design. On the other hand, we showed that HCV infection is an independent factor that promotes arterial stiffening, in spite of the fact that there were no associations between HCV infection and the 
Table 4 Univariate correlations of estimated annual changes in carotid-femoral pulse wave velocity ( $\mathrm{m} \mathrm{s}^{-1}$ per year) and other baseline variables for 148 hemodialysis patients

\begin{tabular}{|c|c|c|}
\hline Parameters & $\begin{array}{l}\text { Correlation } \\
\text { coefficient }\end{array}$ & P-value \\
\hline Age (years) & 0.172 & 0.035 \\
\hline Duration of hemodialysis (months) & 0.007 & 0.931 \\
\hline Body mass index $\left(\mathrm{kg} \mathrm{m}^{-2}\right)$ & -0.027 & 0.742 \\
\hline Systolic blood pressure (mm Hg) & 0.110 & 0.184 \\
\hline Pulse pressure $(\mathrm{mm} \mathrm{Hg})$ & 0.075 & 0.365 \\
\hline Heart rate (b.p.m.) & -0.122 & 0.138 \\
\hline ACEI/ARB use & 0.013 & 0.873 \\
\hline Diabetes mellitus & 0.099 & 0.230 \\
\hline Current smoking & -0.054 & 0.517 \\
\hline Albumin (g per $100 \mathrm{ml}$ ) & -0.008 & 0.920 \\
\hline Calcium (mg per $100 \mathrm{ml}$ ) & 0.002 & 0.980 \\
\hline Phosphate (mg per $100 \mathrm{ml}$ ) & -0.101 & 0.220 \\
\hline Calcium-phosphate product & -0.107 & 0.194 \\
\hline Intact parathormone $\left(\mathrm{ng} \mathrm{ml}^{-1}\right)$ & -0.113 & 0.171 \\
\hline$\beta 2$-microglobulin & -0.007 & 0.936 \\
\hline Total cholesterol (mg per $100 \mathrm{ml}$ ) & 0.092 & 0.269 \\
\hline Triglycerides (mg per $100 \mathrm{ml}$ ) & 0.0001 & 0.999 \\
\hline HDL-C (mg per $100 \mathrm{ml}$ ) & -0.198 & 0.016 \\
\hline LDL-C (mg per 100 ml) & 0.183 & 0.025 \\
\hline LDL-C/HDL-C ratio & 0.256 & 0.002 \\
\hline Hemoglobin A1C (\%) & -0.089 & 0.284 \\
\hline High-sensitive c-reactive protein (mg per $100 \mathrm{ml}$ ) & -0.123 & 0.139 \\
\hline Hepatitis C viral infection & 0.186 & 0.024 \\
\hline $\mathrm{ABPI}$ & -0.289 & $<0.001$ \\
\hline \multicolumn{3}{|l|}{ Relating to complications } \\
\hline Number of macrovascular complications & 0.224 & 0.008 \\
\hline Coronary artery disease & 0.066 & 0.422 \\
\hline Stroke & 0.083 & 0.322 \\
\hline
\end{tabular}

Abbreviations: $\mathrm{ABPI}$, ankle-brachial blood pressure index; $\mathrm{ACEI}$, angiotensin-converting enzyme inhibitor; ARB, angiotensin receptor blocker; HDL-C, high-density lipoprotein cholesterol;

LDL-C, low-density lipoprotein cholesterol.

value of cfPWV at baseline. It is still open to dispute whether HCV infection increases the susceptibility to cardiovascular disease or not. As shown in Table 1, our data showed that patients with and without $\mathrm{HCV}$ infection were not significantly different with regard to the prevalence of macroscopic vascular diseases at baseline and onset of these diseases during the follow-up period. A small number of patients with HCV infection and the relatively short follow-up period could produce an effect, to some extent, on the results of this study. A more large-scaled longitudinal study might be required to elucidate the association between HCV infection and cardiovascular events.

Kalantar-Zadeh et al. ${ }^{16}$ described that the malnutrition-inflammation complex syndrome implicated poor survival and higher cardiovascular mortality of $\mathrm{HCV}$-infected patients among HD patients. In this study, however, surrogates of neither malnutrition nor inflammation were associated with the estimated annual rate of increase in cfPWV, and HCV infection correlated independently with this variable. Moreover, the severity of liver damage, as reflected by ALT, AST, platelet count and serum albumin, did not correlate with the estimated annual change in cfPWV in patients with $\mathrm{HCV}$ infection. Considered collectively, we conclude that HCV viremia per se has a direct role in the progression of aortic stiffening rather than through the malnutrition syndrome induced by liver dysfunction. This interpretation seems to be supported by the results of Ishizaka et al. ${ }^{25}$
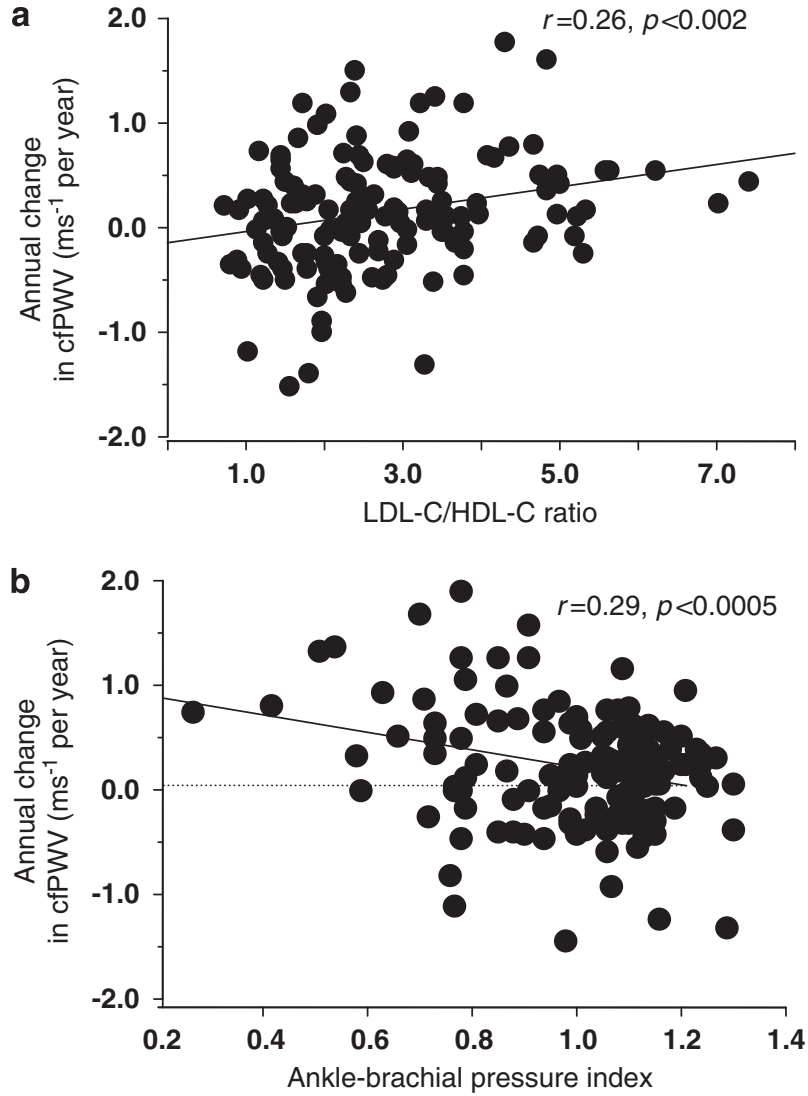

Figure 1 (a) Relationship between the LDL-cholesterol/HDL-cholesterol ratio at baseline and estimated annual change in carotid-femoral pulse wave velocity (cfPWV). (b) Relationship between ankle-brachial blood pressure index at baseline and estimated annual change in carotid-femoral pulse wave velocity (cfPWV).

Table 5 Determinants of annual change in carotid-femoral pulse wave velocity ( $\mathrm{m} \mathrm{s}^{-1}$ per year) analyzed by stepwise regression analysis in a cohort of 148 hemodialysis patients

\begin{tabular}{lccc}
\hline Variable & $\begin{array}{c}\text { Non-standardized } \\
\beta \text { coefficient } \pm \text { s.e.m. }\end{array}$ & $\begin{array}{c}\text { Adjusted } \\
\beta \text { coefficient }\end{array}$ & P-value \\
\hline ABPI & $-0.718 \pm 0.240$ & -0.234 & 0.003 \\
LDL-C/HDL-C ratio & $0.083 \pm 0.033$ & 0.198 & 0.01 \\
Hepatitis C viral infection & $0.322 \pm 0.139$ & 0.177 & 0.02 \\
\hline
\end{tabular}

Abbreviations: HDL-C ratio, high-density lipoprotein cholesterol; LDL-C, low-density lipoprotein cholesterol.

Further studies are required to elucidate the mechanism of $\mathrm{HCV}$ viremia-induced aortic stiffening in patients with ESRD.

In a previous study that investigated changes in arterial stiffness over a 3-year period in middle-aged Japanese men free of renal disease, ${ }^{27}$ elevated blood glucose levels contributed to the progression of arterial stiffness. As for ESRD patients treated with HD, Takenaka et al. ${ }^{28}$ showed that PWV increased more rapidly in diabetic patients than in non-diabetics. Conversely, our present study did not show significant influence for diabetes on the progression of aortic stiffness. 
Although the precise reason for this discrepancy is not clear at present, it may relate to methodological differences. The previous studies measured ankle-brachial pulse wave velocity (ba-PWV), ${ }^{27,28}$ and therefore patients with peripheral arterial disease were probably excluded from the study. Thus, it is possible that participants in those studies were limited to cases with mild arteriosclerosis and that glucose impairment could more greatly affect the progression of mild atherosclerosis. Another possible explanation could be related to the observation that in several diabetic patients with poor blood glucose control at baseline, cfPWV decreased during the follow-up period with improvement in blood glucose control.

There is controversy over the effect of disorders of lipid metabolism on aortic compliance. In several cross-sectional studies, lipid profile was not a determinant of $\mathrm{PWV}, 5,6,9,29$ whereas serum triglyceride correlated positively with ba-PWV in hemodialysis patients ${ }^{30}$ and increments in ba-PWV. ${ }^{28}$ Furthermore, intermediate-density lipoprotein cholesterol, which contains cholesterol and triglyceride, was an independent risk factor for arteriosclerosis. ${ }^{31}$ This study identified the LDL-C/HDL-C ratio as an independent determinant of progression of cfPWV in HD patients. Moreover, logistic regression analysis showed that the LDL-C/HDL-C ratio was a significant predictor of the fall in cfPWV during the follow-up period. Most of our patients were normocholesterolemic, and therefore only five patients had taken statin at the start of this study, and three patients were prescribed the above agent for the first time during the study period. This suggests that values of LDL-cholesterol and/or HDL-cholesterol in the individual patient did not fluctuate markedly during the follow-up period. Thus, we speculate that a persistent rise in the LDL-C/HDL-C ratio, even if not high, may contribute to a worsening of aortic stiffness. Recent research indicates that statins reduce cardiovascular events in normocholesterolemic hypertensive patients. ${ }^{32}$ We could not determine the beneficial effect of this medication on aortic stiffness in this observational study; however, lowering the LDL-C/HDL-C ratio could improve arterial stiffening based on the results of the logistic regression analysis.

One limitation of this study is that we did not determine the longterm effects of some medications that are known to reduce aortic stiffness, for example, lipid-lowering medications such as statins, ${ }^{33}$ angiotensin-converting enzyme blockers, angiotensin receptor II blockers $^{34}$ or sevelamer ${ }^{35}$ on changes in cfPWV. Prospective casecontrol studies are necessary to examine this issue in depth.

In conclusion, in this observational study, we assessed determinants of worsening of cfPWV over a follow-up period of 3 years. Our analysis showed that HCV infection was an independent determinant of progression of aortic stiffening, in addition to the LDL-C/HDL-C ratio and $\mathrm{ABPI}$; however, at this stage, it is not clear how $\mathrm{HCV}$ infection promotes aortic stiffening. Further studies are necessary to investigate the mechanisms of HCV-related enhancement of aortic stiffening.

\section{CONFLICT OF INTEREST}

The author declare no conflict of interest.

1 Brown JH, Hunt LP, Vites NP, Short CD, Gokal R, Mallick NP. Comparative mortality from cardiovascular disease in patients with chrome renal failure. Nephrol Dial Transplant 1994; 9: 1136-1142.

2 Nakai S, Shinzato T, Nagura Y, Masakane I, Kitaoka T, Shinoda T, Yamazaki C, Sakai R, Ohmori H, Morita O, Iseki K, Kikuchi K, Kubo K, Suzuki K, Tabei K, Fushimi K, Miwa N, Wada A, Yanai M, Akiba T. An over view of regular dialysis treatment in Japan (as of 31 December 2004). Ther Apher Dial 2006; 10: 476-497.
3 Shoji T, Emoto M, Shinohara K, Kakiya R, Tsujimoto Y, Kishimoto H, Ishimura E, Tabata T, Nishizawa Y. Diabetes mellitus, aortic stiffness, and cardiovascular mortality in endstage renal disease. J Am Soc Nephrol 2001; 12: 2117-2124.

4 Guerin AP, Blacher J, Pannier B, Marchais SJ, Safar ME, London GM. Impact of aortic stiffness attenuation on survival of patients in end-stage renal failure. Circulation 2001; 103: 987-992.

5 Adragão T, Pires A, Birne R, Curto JD, Lucas C, Gonçalves M, Negrão AP. A plain X-ray vascular calcification score is associated with arterial stiffness and mortality in dialysis patients. Nephrol Dial Transplant 2009; 24: 997-1002.

6 Blacher J, Demuth K, Guerin AP, Safar ME, Moatti N, London GM. Influence of biochemical alterations on arterial stiffness in patients with end-stage renal disease. Arterioscler Thromb Vasc Biol 1998; 18: 535-541.

7 Raggi P, Bellasi A, Ferramosca E, Block GA, Muntner P. Pulse wave velocity is inversely related to vertebral bone density in hemodialysis patients. Hypertension 2007; 49: 1278-1284.

8 Matsumae T, Abe Y, Murakami G, Ishihara M, Ueda K, Saito T. Determinants of aortic wall stiffness and peripheral artery occlusive disease in nondiabetic hemodialysis patients. Hypertens Res 2007; 30: 377-385.

9 Matsumae T, Abe Y, Murakami G, Ueda K, Saito T. Effects of glucose metabolism on aortic pulse wave velocity in hemodialysis patients with and without diabetes. Hypertens Res 2008; 31: 1365-1372.

10 Libby P, Ridker PM, Maseri A. Inflammation and atherosclerosis. Circulation 2002; 105: 1135-1143.

11 Iwashima Y, Horio T, Kamide K, Rakugi H, Ogihara T, Kawano Y. C-reactive protein, left ventricular mass index, and risk of cardiovascular disease in essential hypertension. Hypertens Res 2007; 30: 1177-1185.

12 Chung YM, Park KJ, Choi SY, Hwang SB, Lee SY. Hepatitis C virus core protein potentiates TNF-alpha-induced NF-kappaB activation through TRAF2-IKKbeta-dependent pathway. Biochem Biophys Res Commun 2001; 284: 15-19.

13 Migita K, Abiru S, Maeda Y, Daikoku M, Ohata K, Nakamura M, Komori A, Yano K, Yatsuhashi H, Eguchi K, Ishibashi H. Serum levels of interleukin- 6 and its soluble receptors in patients with hepatitis C virus infection. Hum Immunol 2006; 67: 27-32.

14 Oguchi H, Terashima M, Tokunaga S, Kiyosawa K, Tanaka E, Furuta S, Kanno Y, Aizawa T, Nishioka K. Prevalence of anti-HCV in patients on long-term hemodialysis. Nippon Jinzo Gakkai Shi 1990; 32: 313-317.

15 Fissell RB, Bragg-Gresham JL, Woods JD, Jadoul M, Gillespie B, Hedderwick SA, Rayner HC, Greenwood RN, Akiba T, Young EW. Patterns of hepatitis C prevalence and seroconversion in hemodialysis units from three continents: the DOPPS. Kidney Int 2004; 65: 2335-2342.

16 Kalantar-Zadeh K, McAllister CJ, Miller LG. Clinical characteristics and mortality in hepatitis C-positive haemodialysis patients: a population based study. Nephrol Dial Transplant 2005; 20: 1662-1669.

17 Kalantar-Zadeh K, Kilpatrick RD, McAllister CJ, Miller LG, Daar ES, Gjertson DW, Kopple JD, Greenland S. Hepatitis c virus and death risk in hemodialysis patients. J Am Soc Nephrol 2007; 18: 1584-1592.

18 Kiechl S, Egger G, Mayr M, Wiedermann CJ, Bonora E, Oberhollenzer F, Muggeo M, Xu $Q$, Wick G, Poewe W, Willeit J. Chronic infections and the risk of carotid atherosclerosis: prospective results from a large population study. Circulation 2001; 103: 1064-1070.

19 Adam E, Melnick JL, Probtsfield JL, Petrie BL, Burek J, Bailey KR, McCollum CH, DeBakey ME. High levels of cytomegalovirus antibody in patients requiring vascular surgery for atherosclerosis. Lancet 1987; ii: 291-293.

20 Mendall MA, Goggin PM, Molineaux N, Levy J, Toosy T, Strachan D, Camm AJ, Northfield TC. Relation of Helicobacter pylori infection and coronary heart disease. Br Heart J 1994; 71: 437-439.

21 Yamashiroya HM, Ghosh L, Yang R, Robertson Jr AL. Herpesviridae in the coronary arteries and aorta of young trauma victims. Am J Pathol 1998; 130: 71-79.

22 Völzke H, Schwahn C, Wolff B, Mentel R, Robinson DM, Kleine V, Felix SB, John U. Hepatitis $B$ and $C$ virus infection and the risk of atherosclerosis in a general population. Atherosclerosis 2004; 174: 99-103.

23 Moritani M, Adachi K, Arima N, Takashima T, Miyaoka Y, Niigaki M, Furuta K, Sato S, Kinoshita Y. A study of arteriosclerosis in healthy subjects with HBV and HCV infection. J Gastroenterol 2005; 40: 1049-1053.

24 Momiyama Y, Ohmori R, Kato R, Taniguchi H, Ohsuzu F. Lack of association between persistent hepatitis $\mathrm{B}$ or $\mathrm{C}$ virus infection and coronary artery disease. Atherosclerosis 2005; 181: 211-213.

25 Ishizaka N, Ishizaka Y, Takahashi E, Tooda E, Hashimoto H, Nagai R, Yamakado M. Association between hepatitis $\mathrm{C}$ virus seropositivity, carotid-artery plaque, and intimamedia thickening. Lancet 2002; 359: 133-135.

26 Oyake N, Shimada T, Murakami Y, Ishibashi Y, Satoh H, Suzuki K, Matsumori A, Oda T. Hepatitis $C$ virus infection as a risk factor for increased aortic stiffness and cardiovascular events in dialysis patients. J Nephrol 2008; 21: 345-353.

27 Tomiyama H, Hashimoto H, Hirayama Y, Yambe M, Yamada J, Koji Y, Shiina K, Yamamoto $Y$, Yamashina A. Synergistic acceleration of arterial stiffness in the presence of raised blood pressure and raised plasma glucose. Hypertension 2006; 47: 180-188.

28 Takenaka T, Kobayashi K, Suzuki H. Pulse wave velocity as an indicator of arteriosclerosis in hemodialysis patients. Atherosclerosis 2004; 176: 405-409.

29 Kitahara T, Ono K, Tsuchida A, Kawai H, Shinohara M, Ishii Y, Koyanagi H, Noguchi T, Matsumoto T, Sekihara T, Watanabe Y, Kanai H, Ishida H, Nojima Y. Impact of brachialankle pulse wave velocity and ankle-brachial blood pressure index on mortality in hemodialysis patients. Am J Kidney Dis 2005; 46: 688-696.

30 Nitta K, Akiba T, Uchida K, Otsubo S, Otsubo Y, Takei T, Ogawa T, Yumura W, Kabaya T, Nihei $H$. Left ventricular hypertrophy is associated with arterial stiffness and vascular calcification in hemodialysis patients. Hypertension Res 2004; 27: 47-52. 
31 Shoji T, Nishizawa Y, Kawagishi T, Kawasaki K, Taniwaki H, Tabata T, Inoue T, Morii $\mathrm{H}$. Intermediate-density lipoprotein as an independent risk factor for aortic atherosclerosis in hemodialysis patients. J Am Soc Nephrol 1998; 9: 1277-1284.

32 Sever PS, Dahlöf B, Poulter NR, Wedel H, Beevers G, Caulfield M, Collins R, Kjeldsen SE, Kristinsson A, Mclnnes GT, Mehlsen J, Nieminen M, O'Brien E, Ostergren J, ASCOT investigators. Prevention of coronary and stroke events with atorvastatin in hypertensive patients who have average or lower-than-average cholesterol concentrations, in the Anglo-Scandinavian Cardiac Outcomes Trial-Lipid Lowering Arm (ASCOT-LLA): a multicentre randomised controlled trial. Lancet 2003; 361: 1149-1158.
33 Mäki-Petäjä KM, Booth AD, Hall FC, Wallace SM, Brown J, McEniery CM, Wilkinson IB. Ezetimibe and simvastatin reduce inflammation, disease activity, and aortic stiffness and improve endothelial function in rheumatoid arthritis. J Am Coll Cardiol 2007; 50: 852-858.

34 Ichihara A, Hayashi M, Kaneshiro Y, Takemitsu T, Homma K, Kanno Y, Yoshizawa M, Furukawa T, Takenaka T, Saruta T. Low doses of losartan and trandolapril improve arterial stiffness in hemodialysis patients. Am J Kidney Dis 2005; 45: 866-874.

35 Othmane Tel H, Bakonyi G, Egresits J, Fekete BC, Fodor E, Jarai Z, Jekkel C, Nemcsik J, Szabo A, Szabo T, Kiss I, Tisler A. Effect of sevelamer on aortic pulse wave velocity in patients on hemodialysis: a prospective observational study. Hemodial Int 2007; 11 (Suppl 3): S13-S21. 